\title{
Гипопаратиреоз: этиология,
}

\section{клиническая картина, современные методы диагностики и лечения}

\author{
Мокрышева Н.Г.' • Еремкина А.К. • Ковалева Е.В. ${ }^{1}$
}

\author{
Мокрышева Наталья Георгиевна - \\ д-р мед. наук, руководитель Центра \\ патологии околощитовидных желез' \\ Еремкина Анна Константиновна - \\ канд. мед. наук, науч. сотр., Центр \\ патологии околощитовидных желез' \\ $\triangle 117036$, г. Москва, ул. Дмитрия \\ Ульянова, 11, Российская Федерация. \\ Тел.: +7 (495) 5000063. \\ E-mail: parathyroid.enc.@gmail.com
}

Ковалева Елена Владимировна клинический ординатор'
'ФГБУ «Эндокринологический научный центр» Минздрава России; 117036, г. Москва, ул. Дмитрия Ульянова, 11, Российская Федерация
Главным регулятором фосфорно-кальциевого обмена является паратиреоидный гормон (паратгормон, ПТГ). Недостаточность ПТГ или резистентность тканей к его действию приводит к развитию гипопаратиреоза, характеризующегося гипокальциемией и гиперфосфатемией. Наиболее часто встречается послеоперационный гипопаратиреоз, обусловленный повреждением или удалением околощитовидных желез, нарушением их кровоснабжения в ходе хирургического вмешательства в области шеи, в основном по поводу заболеваний щитовидной железы. Вторая по распространенности форма заболевания, обусловленная иммуноопосредованным разрушением клеток околощитовидных желез, - аутоиммунный гипопаратиреоз. К более редким причинам гипопаратиреоза относят различные генетические нарушения, дефекты митохондриального генома, гипомагниемию. Основные клинические проявления гипопаратиреоза обусловлены гипокальциемией и гиперфосфатемией, приводящими к увеличению нервно-мышечной возбудимости и общей вегетативной реактивности, и включают в себя парестезии в акральных областях, фибриллярные подергивания, тонические судороги, ларинго- и бронхоспазм, неврозы. Проявление этих симптомов тесно связано с уровнем кальция в сыворотке крови; степень их выраженности зависит от тяжести гипокальциемии. Лабораторными показателями, подтверждающими диагноз гипопаратиреоза, являются гипокальциемия, гиперфосфатемия, снижение уровня ПТГ в сыворотке крови.
Лечение гипопаратиреоза подразделяется на купирование тетанического гипокальциемического криза и поддерживающую терапию. Для купирования острой гипокальциемии используют внутривенное введение глюконата кальция с одновременным назначением препаратов кальция и активных метаболитов. Стандартная терапия хронического гипопаратиреоза включает в себя пероральное применение солей кальция и активных метаболитов/ аналогов витамина D и направлена на поддержание баланса между оптимальной низконормальной концентрацией кальция в сыворотке крови и нормокальциурией. Повышение экскреции кальция с мочой часто недооценивается специалистами, хотя гиперкальциурия может приводить к развитию тяжелой почечной патологии - нефрокальциноза и нефролитиаза. Гипопаратиреоз - одна из немногих эндокринопатий, для которых заместительная терапия рекомбинантным паратгормоном пока не нашла широкого применения. Заместительная терапия препаратами рекомбинантного человеческого ПТГ - перспективное направление, особенно в тяжелых клинических случаях, рефрактерных к традиционной терапии.

Ключевые слова: гипопаратиреоз, псевдогипопаратиреоз, паратиреоидный гормон, гипокальциемия, гиперфосфатемия, рекомбинантный человеческий паратиреоидный гормон 1-84

doi: 10.18786/2072-0505-2016-44-4-477-492 
$\Gamma$ ипопаратиреоз - состояние, характеризующееся сниженной продукцией паратиреоидного гормона (ПТГ) околощитовидными железами или резистентностью тканей к его действию, что приводит к различным нарушениям, прежде всего фосфорно-кальциевого обмена.

Паратиреоидный гормон (паратгормон) главный регулятор обмена кальция и фосфора представляет собой одноцепочечный полипептид из 84 аминокислотных остатков. Его действие направлено на повышение концентрации ионов кальция и снижение концентрации фосфатов в плазме крови. В свою очередь, секреция ПТГ регулируется за счет воздействия ионов кальция на G-белок кальцийчувствительного рецептора (calcium-sensing receptor - CASR), локализованного на мембране клеток околощитовидных желез. Гипокальциемия приводит к усилению секреции ПТГ, гиперкальциемия - к снижению его выработки $[1,2]$.

Основными органами-мишенями для ПТГ становятся почки и костная ткань. В органах-мишенях локализованы специфические рецепторы PTH/PTHrP, которые взаимодействуют с ПТГ, вследствие чего инициируется каскад событий с активацией аденилатциклазы. Внутри клетки возрастает концентрация молекул циклического аденозинмонофосфата, действие которых стимулирует мобилизацию ионов кальция из внутриклеточных запасов. В почках ПТГ действует преимущественно в восходящем отделе петли Генле и дистальных извитых канальцах. ПТГ увеличивает реабсорбцию кальция путем увеличения активности $\mathrm{Ca}^{2+}$-аденозинтрифосфатазы и $\mathrm{Na}^{+}-\mathrm{Ca}^{2+}$-противотока, а также посредством стимуляции 1а-гидроксилазы и синтеза кальцитриола. В костной ткани рецепторы РТН/PTHrP локализованы на остеобластах и остеоцитах, но отсутствуют на остеокластах. Тем не менее при повышении уровня ПТГ происходит активация остеокластов и усиливается резорбция костной ткани. Этот эффект ПТГ опосредуется остеобластами: под влиянием ПТГ стимулируется секреция инсулиноподобного фактора роста 1 и цитокинов (интерлейкина-1 и гранулоцитарно-макрофагального колониестимулирующего фактора), которые активируют остеокласты [2-4].

Еще один важнейший регулятор фосфорно-кальциевого обмена - кальцитриол. Подобно другим стероидным гормонам, он связывается с внутриклеточным рецептором клетки-мишени. Образуется комплекс «гормон - рецептор», который взаимодействует с хроматином и индуцирует транскрипцию структурных генов, в результате чего синтезируются белки, опосредующие действие кальцитриола. В энтероцитах кальцитриол индуцирует синтез $\mathrm{Ca}^{2+}$-переносящих белков, обеспечивающих реабсорбцию ионов кальция и фосфатов из полости кишечника в эпителиальную клетку кишечника. Далее кальцитриол контролирует транспорт ионов кальция из клетки в кровь. Благодаря этому их концентрация во внеклеточной жидкости поддерживается на уровне, необходимом для минерализации органического матрикса костной ткани. В почках кальцитриол стимулирует реабсорбцию ионов кальция и фосфатов [2-4].

В кальциевом обмене также участвует кальцитонин - полипептид, состоящий из 32 аминокислотных остатков с одной дисульфидной связью. Гормон секретируется парафолликулярными клетками щитовидной железы и С-клетками околощитовидных желез в виде высокомолекулярного белка-предшественника. Секреция кальцитонина возрастает при повышении сывороточной концентрации кальция и, наоборот, уменьшается при его снижении. Кальцитонин - антагонист паратгормона, он ингибирует высвобождение $\mathrm{Ca}^{2+}$ из кости, снижая активность остеокластов. Кроме того, кальцитонин подавляет канальцевую реабсорбцию ионов кальция в почках, тем самым стимулируя их экскрецию почками с мочой [4].

\section{Эпидемиология и этиология}

Последние данные о распространенности гипопаратиреоза представлены в крупном датском исследовании (обследовано 2000 человек), согласно результатам которого частота составляет около 22 случаев на 100000 населения в год. Основное место среди причин гипопаратиреоза занимают послеоперационные нарушения функции околощитовидных желез. Другие формы гипопаратиреоза встречаются значительно реже - в 8\% наблюдений (2 / 100000 населения) [5]. Представленные данные согласуются с результатами эпидемиологического исследования американской популяции. Распространенность заболевания составила около 37 случаев на 100000 населения с преобладанием послеоперационного гипопаратиреоза [6]. В России подобных данных нет в связи с отсутствием скрининга гипокальциемии.

\section{Послеоперационный гипопаратиреоз}

Наиболее часто встречается гипопаратирео3, обусловленный повреждением или удалением околощитовидных желез, нарушением их 
кровоснабжения в ходе хирургического вмешательства [6]. Предрасполагающими факторами считаются: большой объем операции, отсутствие опыта хирурга, реоперации, отсутствие четких топических данных о локализации околощитовидных желез. Наиболее часто послеоперационный гипопаратиреоз развивается после хирургического лечения рака щитовидной железы и диффузного токсического зоба [7-9]. Он может также возникать после хирургического лечения по поводу первичного гиперпаратиреоза, когда удаляется доминирующая паратиреоидная ткань и оставшиеся околощитовидные железы не способны восстановить достаточную продукцию ПТГ [10].

Послеоперационный гипопаратиреоз проявляется в виде гипокальциемии, обнаруживаемой в течение 24 часов после проведенного хирургического вмешательства на области шеи у 30-60\% пациентов. Около 60-70\% случаев послеоперационной гипокальциемии имеют транзиторный характер и разрешаются в течение 4-6 недель после операции (транзиторный гипопаратиреоз). Стойкая гипокальциемия в сочетании с уровнем ПТГ ниже референсных значений спустя 6 месяцев и более после хирургического лечения свидетельствует о развитии хронического гипопаратиреоза $[2,11]$. Риск хронического гипопаратиреоза тесно связан с количеством оставшихся in situ функционирующих околощитовидных желез во время операции: 16\% при сохраненных 1-2 железах, 6\% при 3 железах и 2,5\% при $4[12,13]$.

\section{Аутоиммунный гипопаратиреоз}

Вторая по распространенности форма гипопаратиреоза, обусловленная иммуноопосредованным разрушением клеток околощитовидных желез, - аутоиммунный гипопаратиреоз. Он может быть изолированным заболеванием, однако значительно чаще встречается в рамках наследственного аутоиммунного полигландулярного синдрома (АПС) 1-го типа, также известного как кандидо-эктодермальная дистрофия (Autoimmune Polyendocrinopathy with Candidiasis and Ectodermal Dystrophy - APECED) [6].

АПС 1-го типа - моногенное аутосомно-рецессивное заболевание, в основе которого лежит нарушение структуры гена аутоиммунного регулятора $(A I R E)$. Ген $A I R E$ располагается на длинном плече 21-й хромосомы, кодирует ядерный фактор транскрипции и играет одну из ключевых ролей в формировании иммунотолерантности. В основе патогенеза лежит аутоиммунная деструкция различных эндокринных желез [14]. Для АПС 1-го типа характерна классическая триада: слизисто-кожный кандидоз, гипопаратиреоз, хроническая надпочечниковая недостаточность. Заболевание дебютирует, как правило, в детском возрасте. В подавляющем большинстве случаев начальным проявлением становится слизисто-кожный кандидоз, развивающийся в первые 10 лет жизни, чаще в возрасте около 2 лет. На фоне слизисто-кожного кандидоза у $84 \%$ пациентов появляется гипопаратиреоз, при этом в 88\% случаев он дебютирует в возрасте до 10 лет. К другим компонентам синдрома относятся сахарный диабет 1-го типа, тиреоидит Хашимото, целиакия, витилиго, аутоиммунный гепатит, гипогонадизм и другие [15].

В настоящее время остается неизвестным, что выступает мишенью для аутоиммунного повреждения клеток околощитовидных желез. В литературе рассматривается несколько антигенов, аутоантитела к которым могут быть ответственны за развитие гипопаратиреоза. В 1996 г. Y. Li и соавт. впервые выявили активирующие антитела к кальцийчувствительному рецептору CASR. В исследование были включены 25 пациентов, среди которых у 17 причиной гипопаратиреоза был АПС 1-го типа, а у 8 человек отмечалось сочетание гипопаратиреоза и аутоиммунного тиреоидита. В результате у 56\% пациентов с гипопаратиреозом определялись высокие титры антител к CASR, тогда как в группе контроля эти антитела не были найдены ни у одного человека [16]. Однако в ряде других работ корреляции между активирующими антителами к CASR и гипопаратиреозом у пациентов с AПC 1-го типа выявлено не было [17]. Антитела к CASR, но обладающие блокирующей способностью, также были обнаружены при аутоиммунной гипокальциурической гиперкальциемии [18].

NALP5 - мультипротеиновый комплекс, активирующий внутриклеточные киназы и синтез провоспалительных цитокинов, включает в себя: NACHT (neuronal apoptosis inhibitor protein), C2TA (MHC class 2 transcription activator), HET-E (incompatibility locus protein from Podospora anserina) и TP1 (telomerase-associated protein), впервые обнаружен M. Alimohammadi и соавт. [19] в качестве специфического антигена околощитовидных желез. Всего были обследованы 87 пациентов с АПС 1-го типа, из которых у 73 отмечался гипопаратиреоз. Среди пациентов с гипопаратиреозом антитела к NALP5 идентифицированы в $49 \%$ наблюдений, у пациентов с АПС 1-го типа без снижения функции околощитовидных желез данные антитела обнаружены не были [19]. Подобные результаты получены в работе A. Meloni и соавт.: антитела к NALP5 выявлены 
у 64,3\% пациентов с гипопаратиреозом и не определялись у пациентов без гипопаратиреоза [20]. Тем не менее вопрос о роли специфических антигенов в развитии аутоиммунного поражения околощитовидных желез остается открытым и требует дальнейшего изучения [21].

\section{Генетические варианты изолированного гипопаратиреоза}

В зависимости от патогенеза заболевания генетические варианты изолированного гипопаратиреоза условно могут быть разделены на три основные группы. В первую группу входят заболевания, характеризующиеся нормальным развитием околощитовидных желез, но нарушенной секрецией ПТГ. К данной группе относится аутосомно-доминантная гипокальциемия, в основе которой лежат активирующие точечные мутации гена $C A S R$, например, делеция изолейцина внутри рамки считывания консервативного фрагмента $G \alpha 11$. В настоящее время описано около 40 активирующих мутаций. Ген CASR впервые клонирован в 1993 г. [22]. Он локализован в длинном плече 3-й хромосомы. Продукт гена представляет собой рецептор из суперсемейства рецепторов, сопряженных с G-белками. Связывание CASR с лигандами стимулирует активность фосфолипазы C, что приводит к аккумуляции инозитол-1,4,5-трифосфата и к возрастанию концентрации кальция $\left(\mathrm{Ca}^{2+}\right)$ в цитозоле [23]. Активация рецепторного белка приводит к нарушению регуляции секреции ПТГ по принципу обратной связи, когда нормальные или низкие показатели уровня кальция сопровождаются снижением выработки гормона. Для заболевания характерна умеренная гипокальциемия в сочетании со снижением уровня ПТГ, у большинства пациентов наблюдается гипомагниемия. Течение заболевания сопровождается судорогами, иногда карпопедальными спазмами, но может быть и асимптоматичным. Чрезвычайно важно отличить аутосомно-доминантную гипокальциемию от первичного гипопаратиреоза, так как назначение витамина D может приводить к появлению гиперкальциурии, развитию нефрокальциноза и нарушению почечных функций. Описаны также пациенты, у которых активирующие ген CASR мутации вызывают Барттер-подобный синдром, то есть наряду со снижением уровня магния, кальция и ПТГ у них наблюдается нефрогенная потеря минеральных солей и воды, ассоциированная с гипокалиемическим алкалозом $[24,25]$. В этих случаях $\mathrm{Ca}^{2+} / \mathrm{Mg}^{2+}$ чувствительные рецепторы активированы даже при физиологической концентрации кальция в сыворотке. При этом уменьшение реабсорбции $\mathrm{NaCl}$ в толстом сегменте восходящей части петли Генле приводит к вторичному гиперальдостеронизму и гипокалиемии.

Аномалии развития околощитовидных желез относятся ко второй группе заболеваний, возникающих в результате мутации транскрипционных факторов. Дефект гена GCM2 (glial cell missing 2) лежит в основе нарушения формирования околощитовидных желез и наследуется по аутосомно-рецессивному типу. Х-сцепленный рецессивный вариант связывают с делециями и инсерциями на участке Хq27.1. Предположительно, указанные мутации влияют на функцию белка SoX9 - транскрипционного фактора, имеющего значение в развитии околощитовидных желез [26].

В третью группу можно включить мутации гена ПТГ, приводящие к нарушению его процессинга и секреции и сопровождающиеся развитием изолированного гипопаратиреоза. Данные мутации встречаются достаточно редко, имеют аутосомно-рецессивный и аутосомно-доминантный типы наследования. Нарушается посттрансляционная обработка молекулы препропаратгормона и/или трансляции матричной рибонуклеиновой кислоты. Секвенирование дезоксирибонуклеиновой кислоты у пациентов с аутосомно-доминантным изолированным гипопаратиреозом выявило единственную миссенс-мутацию с заменой тимина на цитозин во 2-м экзоне, 18-м кодоне [27]. Гомозиготные мутации гена препропаратгормона приводят к значимому снижению уровня ПТГ (вплоть до неопределяемых значений) в сочетании с симптоматической гипокальциемией и гиперфосфатемией [28].

\section{Гипопаратиреоз в составе поликомпонентных генетических заболеваний}

Гипопаратиреоз может входить в состав поликомпонентных генетических заболеваний. Синдром Ди Джорджи вызван делецией 22q11. Для данного заболевания характерны дисморфия, врожденные пороки сердца и тяжелый иммунодефицит. Гипопаратиреоз связан с врожденной дисгенезией околощитовидных желез. Аплазия или дисплазия околощитовидных желез, дисплазия тимуса возникают вследствие нарушений эмбриогенеза 3-го и 4-го глоточных карманов. Больные обычно погибают в детском возрасте [29]. Синдром Бараката, или HDR-синдром (hypoparathyroidism, deafness and renal dysplasia syndrome) - аутосомно-доминантное заболевание, вызванное дефектом гена GATA3, локализованного в коротком плече 10-й хромосомы 
Таблица 1. Основные генетические причины развития гипопаратиреоза

\begin{tabular}{|c|c|}
\hline Заболевание & Дефекты в гене/локус \\
\hline \multicolumn{2}{|l|}{ Изолированный гипопаратиреоз } \\
\hline аутосомно-рецессивный & $\begin{array}{l}\text { PTH/11p15 } \\
\text { GCMB/6p24.2 }\end{array}$ \\
\hline аутосомно-доминантный & $\begin{array}{l}\text { PTH/11p15 } \\
\text { CsSR/3q21.1 } \\
\text { GCMB/6p24.2 }\end{array}$ \\
\hline X-сцепленный & SOX3/Xq26-27 \\
\hline \multicolumn{2}{|c|}{$\begin{array}{l}\text { Гипопаратиреоз в составе поликомпонентных генетических } \\
\text { заболеваний }\end{array}$} \\
\hline синдром Ди Джорджи & $T B X 1 / 22 q 11$ \\
\hline синдром Бараката (HDR-синдром) & GATA3/10p15 \\
\hline синдром Саньяд - Сакати (HRD-синдром) & $T B C E / 1 \mathrm{q} 42-43$ \\
\hline Аутоиммунный полигландулярный синдром 1-го типа & AIRE/21q22.3 \\
\hline \multicolumn{2}{|l|}{ Гипопаратиреоз и дефекты митохондриального генома } \\
\hline синдром Кернса - Сейра & $\begin{array}{l}\text { Дефекты } \\
\text { митохондриального }\end{array}$ \\
\hline синдром MELAS & генома \\
\hline \multicolumn{2}{|l|}{ синдром MTPD } \\
\hline \multicolumn{2}{|l|}{ Резистентность к действию паратгормона } \\
\hline псевдогипопаратиреоз & GNAS/20q13.3 \\
\hline \multicolumn{2}{|l|}{ тип 1а } \\
\hline \multicolumn{2}{|l|}{ тип $1 b$} \\
\hline хондродисплазия Бломстранда & PTHR1/3p22-p21.1 \\
\hline
\end{tabular}

HDR - hypoparathyroidism, deafness and renal dysplasia (гипопаратиреоз, глухота и дисплазия почек), HRD - hypoparathyroidism-retardation-dysmorphism (гипопаратиреоз, задержка развития, дисморфизм), MELAS - mitochondrial encephalopathy, lactic acidosis and stroke-like episodes (митохондриальная миопатия и энцефалопатия с лактат-ацидозом и инсультоподобными эпизодами), MTPD - mitochondrial trifunctional protein deficiency syndrome (недостаточность митохондриального трифункционального белка)

(10p15). Ген кодирует белок, отвечающий за развитие паратиреоидных желез, внутреннего уха, почек. Уровень ПТГ колеблется от нижней границы нормы до неопределяемого [30]. Синдром Кенни - Каффи включает в себя низкорослость, аномалии глаз, остеосклероз. Синдром Саньяд Сакати, или синдром HRD (hypoparathyroidismretardation-dysmorphism), часто рассматривается как вариант синдрома Кенни - Каффи. Он проявляется гипопаратиреозом, тяжелой задержкой физического и психомоторного развития, микроцефалией, особенностями фенотипа.
У пациентов с синдромами Кенни - Каффи 1-го типа (аутосомно-рецессивное наследование) и Саньяд - Сакати выявляют мутации в гене TBCE (tubulin-specific chaperone E) [31].

Гипопаратиреоз является компонентом некоторых болезней митохондриальной дезоксирибонуклеиновой кислоты и особенно характерен для синдрома Кернса - Сейра в сочетании с наружной офтальмоплегией, пигментной дегенерацией сетчатки, миопатией, кардиомиопатией. При синдроме MELAS (mitochondrial encephalopathy, lactic acidosis and stroke-like episodes) гипопаратиреоз сочетается с митохондриальной энцефалопатией, лактат-ацидозом, инсультоподобными эпизодами. Несмотря на то что при этих заболеваниях гипопаратиреоз, как правило, не выступает единственным или основным проявлением, в ряде случаев в дебюте развиваются гипокальциемические судороги, что служит поводом для обследования [32]. Дефицит магния может привести к развитию гипокальциемии и функционального гипопаратиреоза.

\section{Псевдогипопаратиреоз}

Наследственная остеодистрофия Олбрайта, или псевдогипопаратиреоз, - генетически гетерогенное заболевание. В большинстве случаев его развитие связано с мутациями гена GNAS1 (расположен на 20-й хромосоме, локус 20q13), который кодирует белок Gs-альфа, связанный с рецептором ПТГ. В основе патогенеза псевдогипопаратиреоза лежит генетически детерминированная резистентность тканей-мишеней (скелета и почек) к эффектам ПТГ в результате дефекта комплекса «специфический клеточный рецептор ПТГ - аденилатциклаза». У одних пациентов определяются дефекты самого клеточного рецептора, связывающего ПТГ (тип 1А псевдогипопаратиреоза), у других отмечается дефект нуклеотидсвязывающего белка, локализованного в липидном бислое клеточной мембраны и функционально связывающего рецептор с аденилатциклазой (тип 1В псевдогипопаратиреоза). У некоторых больных наблюдается ферментативная недостаточность аденилатциклазы (псевдогипопаратиреоз 2-го типа). Дефицит циклического аденозинмонофосфата, развивающийся вследствие этих дефектов, ведет к нарушению синтеза специфических белков, определяющих биологический эффект ПТГ. Таким образом, теряется чувствительность органов-мишеней к действию гормона [33, 34]. Основные генетические причины развития гипопаратиреоза представлены в табл. 1. 
Таблица 2. Клинические симптомы гипопаратиреоза

\begin{tabular}{|c|c|}
\hline Системы органов & Клинические проявления \\
\hline Опорно-двигательная система & $\begin{array}{l}\text { Фибриллярные подергивания, тонические судороги, тетания, карпопедальный спазм, симптомы Хвостека } \\
\text { и Труссо }\end{array}$ \\
\hline Дыхательная система & Ларингоспазм и бронхоспазм \\
\hline Желудочно-кишечный тракт & Дисфагия, рвота, диарея и запоры \\
\hline Сердечно-сосудистая система & Удлинение интервала Q-Т и неспецифические изменения зубца Т, гипокальциемическая кардиомиопатия \\
\hline Вегетативная нервная система & $\begin{array}{l}\text { Жар, озноб, головокружения, головные боли, парестезии (чаще пальцев рук, ног, области вокруг рта), } \\
\text { потливость, стойкий дермографизм, нарушения зрительной аккомодации, боли в области сердца с картиной } \\
\text { коронароспазма и нарушениями ритма }\end{array}$ \\
\hline Центральная нервная система & Невроз, снижение памяти, бессонница, депрессия \\
\hline
\end{tabular}

\section{Гипопаратиреоз и гипомагниемия}

Паратгормон усиливает реабсорбцию магния в дистальном канальце и в клетках мозговой части дистального извитого канальца. Повышение концентрации магния или кальция в плазме активирует внеклеточные $\mathrm{Ca}^{2+} / \mathrm{Mg}^{2+}$ чувствительные рецепторы, что сопровождается ингибированием накопления циклического аденозинмонофосфата и уменьшением поглощения магния клетками мозговой части дистального извитого канальца. Снижение концентрации магния в плазме увеличивает реабсорбцию $\mathrm{Mg}^{2+}$, не влияя на абсорбцию кальция. Такая селективность клеток обеспечивает чувствительный контроль транспорта магния в дистальных извитых канальцах. Исходя из вышеизложенного, при снижении уровня магния в сыворотке, как и при гипокальциемии, секреция ПТГ должна усиливаться, однако дефицит магния приводит к патологическому снижению уровня ПТГ и развитию резистентности костной ткани и почек к его эффектам [35]. Патогенетический механизм развития гипопаратиреоза при гипомагниемии остается неизвестным. Потеря магния наблюдается вследствие желудочно-кишечных расстройств, при алкоголизме и ряде других состояний. Существуют наследственные формы гипомагниемии.

Аутосомно-рецессивная гипомагниемия с вторичной гипокальциемией впервые описана L. Paunier и соавт. [36]. Заболевание проявляется в младенческом возрасте и характеризуется исключительно низкими уровнями магния и кальция сыворотки крови. Оно обусловлено мутациями в гене TRPM6, приводящими к нарушению активного транспорта магния клетками кишечного эпителия. Механизм вторичной гипокальциемии остается неясным. Гипокальциемия у данной группы пациентов не поддается лечению препаратами кальция, витамином D или рекомбинантным ПТГ. Нормализация уровня кальция и ПТГ достигается только после коррекции сывороточного магния. Предполагается, что выраженная гипомагнезиемия приводит к определенной резистентности органов-мишеней к эффектам ПТГ.

В развитии гипомагниемии определенная роль отводится активирующим мутациям гена CASR, так как снижение уровня магния выявляется в рамках аутосомно-доминантной гипокальциемии (см. выше) [22]. Мутации, инактивирующие ген CASR (у пациентов с семейной гиперкальциемией и гипокальциурией), наоборот, приводят к снижению экскреции кальция и магния почками, что может также сопровождаться развитием гипермагниемии [37]. Вероятно, дальнейшее изучение наследственных нарушений гомеостаза магния сможет пролить свет на патогенетические основы формирования гипокальциемии при снижении его уровня.

\section{Клиническая картина}

Основные клинические проявления гипопаратиреоза обусловлены гипокальциемией и гиперфосфатемией, приводящими к увеличению нервно-мышечной возбудимости и общей вегетативной реактивности, и включают в себя парестезии в акральных областях, фибриллярные подергивания, тонические судороги, ларингои бронхоспазм, неврозы. Проявление этих симптомов тесно связано с уровнем кальция в сыворотке крови; степень их выраженности зависит от тяжести гипокальциемии. Однако клинические проявления гипокальциемии могут быть весьма 
многообразными: от малосимптомных при стабильно низких показателях уровня кальция в сыворотке крови в течение многих лет вплоть до развития тетании при неустойчивых показателях кальция в сыворотке крови $[1,2]$.

При снижении уровня кальция сыворотки крови до 2-2,2 ммоль/л (средние нормативные значения составляют от 2,25 до 2,75 ммоль/л) гипокальциемия может протекать бессимптомно [1]. Клинические симптомы гипопаратиреоза обобщены в табл. 2.

Умеренное повышение нервно-мышечной возбудимости проявляется скрытой тетанией, характеризующейся положительными симптомами Труссо и Хвостека. Положительный симптом Труссо предполагает появление судорог в кисти («рука акушера») через 1-3 минуты после сдавления плеча манжетой для измерения артериального давления [38]. Данный симптом - высокочувствительный и специфичный признак гипокальциемии - выявляется у 94\% пациентов с гипокальциемией и у $1 \%$ людей с нормокальциемией [39]. Симптом Хвостека - сокращение мышц лица при постукивании в месте выхода лицевого нерва - менее чувствительный и специфичный признак. Отрицательный симптом Хвостека наблюдается у $30 \%$ пациентов, имеющих гипокальциемию, положительный - у $10 \%$ человек без этой патологии $[1,2,38]$.

При длительной выраженной гипокальциемии возникают трофические нарушения и могут развиваться катаракта, дефекты эмали зубов, сухость кожи, ломкость ногтей. Достаточно быстро развиваются изменения психики, проявляющиеся неврозом, снижением памяти, бессонницей, депрессией. Могут отмечаться вегетативные нарушения (жар, озноб, головокружения, боли

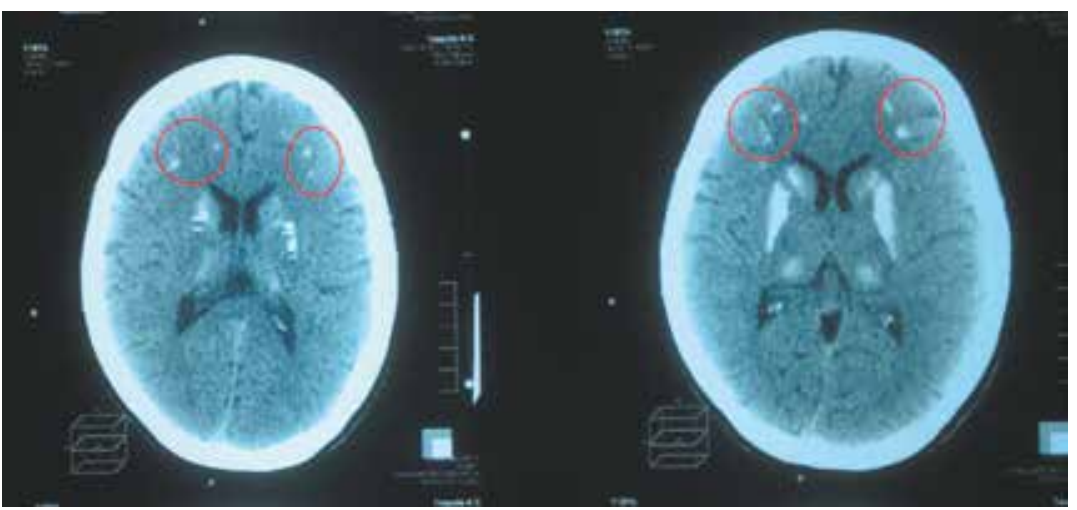

Рис. 1. Компьютерная томография пациента Ц. с хроническим гипопаратиреозом в рамках аутоиммунного полигландулярного синдрома 1-го типа, красным выделены кальцификаты базальных ганглиев (источник - архив Н.Г. Мокрышевой и соавт.) в области сердца). Хроническая гипокальциемия лежит в основе кальцификации мягких тканей, что, вероятнее всего, может быть следствием усиления реабсорбции фосфора в проксимальных почечных канальцах и хронической гиперфосфатемии. Наиболее типичная локализация кальцификации - головной мозг (базальные ганглии, рис. 1) и почки (нефрокальциноз). В ряде случаев отмечается эктопическое отложение кальция в хрящевую ткань, глаза, кожу, сосуды и другие органы и системы [2].

Важное значение для прогноза риска летальности пациентов с гипопаратиреозом имеют сердечно-сосудистые нарушения. Гипокальциемическая кардиомиопатия, возникающая при гипопаратиреозе, чаще относится к дилатационной кардиомиопатии, сопровождается расширением камер сердца и снижением фракции выброса. В среднем по данным литературы фракция выброса снижается на 25-30\% от исходных значений, однако в ряде случаев фракция выброса составляла 17\%. Возникновение и нарастание явлений сердечной недостаточности могут происходить как остро, так и постепенно, причем в любом возрасте (средний возраст - 49 лет) [40]. Кардиопатия при гипопаратиреозе сопровождается электрокардиографическими признаками гипокальциемии: удлинением интервала Q-T, изменениями Т-зубца (сходные изменения при инфаркте миокарда без Q-зубца), желудочковыми нарушениями ритма, которые нередко могут быть единственными проявлениями сердечно-сосудистой патологии [41]. Описаны случаи значительного удлинения интервала Q-T и развития желудочковых нарушений ритма, вплоть до фибрилляции желудочков [42]. Застойная сердечная недостаточность у пациентов с гипокальциемией развивается редко, чаще не поддается традиционному лечению, но частично или полностью обратима после нормализации уровня кальция.

В литературе представлено крайне мало исследований, посвященных анализу факторов риска и патогенеза кальцификации и атеросклеротических изменений сосудов при гипопаратиреозе. У пациентов с гипопаратиреозом отмечается увеличение толщины комплекса интима-медиа в сонных, почечных артериях и аорте, таким образом, значимо повышены маркеры сердечно-сосудистого риска. Но убедительные данные о взаимосвязи указанных изменений с показателями фосфорно-кальциевого обмена отсутствуют $[43,44]$. По данным Р. Agarwal и соавт. [45], в 10\% случаев при гипопаратиреозе 
отмечается повышение уровня коронарного кальция той или иной степени выраженности. Согласно результатам исследования, индекс коронарного кальция коррелирует с уровнем альбуминскорректированного кальция; связи с гиперфосфатемией, низким уровнем паратгормона и высоким сердечно-сосудистым риском продемонстрировано не было. Не исключено, что выявленные авторами изменения в сонных, почечных артериях и аорте, а также повышение индекса коронарного кальция у пациентов с гипопаратиреозом обусловлены длительным приемом препаратов кальция и витамина D [45]. Результаты метаанализа трех плацебоконтролируемых исследований продемонстрировали статистически значимое повышение риска развития инфаркта миокарда $(\mathrm{p}=0,05)$ и комбинации инфаркта миокарда и инсульта $(\mathrm{p}=0,02)$ на фоне длительного приема препаратов кальция и витамина D [46]. Необходимы дальнейшие исследования, направленные на изучение механизмов сердечно-сосудистого риска у пациентов с хроническим гипопаратиреозом.

Состояние костного обмена при гипопаратиреозе характеризуется замедлением костного ремоделирования и нарушением микроархитектоники костной ткани у пациентов с гипопаратиреозом, что ведет к повышению риска переломов $[47,48]$. В связи с отсутствием полномасштабных исследований риска переломов у пациентов с гипопаратиреозом клиническое значение аномальной микроархитектоники остается предметом дискуссий [49-54]. Оценка минеральной плотности кости (МПК) методом двухэнергетической рентгеновской абсорбциометрии свидетельствует о некотором повышении этого показателя, особенно в участках с преобладанием трабекулярной

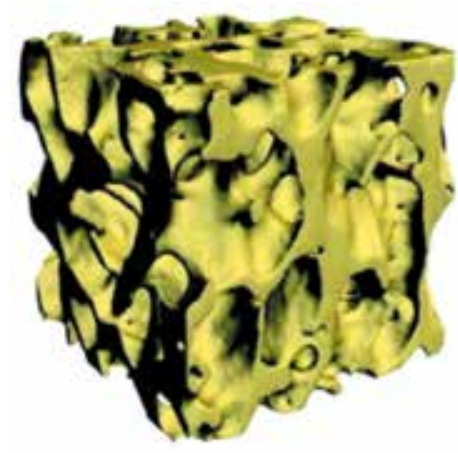

Гипопаратиреоз
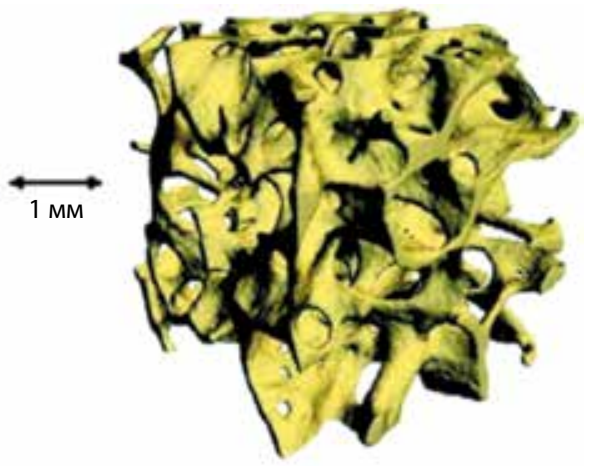

Контроль
Рис. 2. Реконструкция 3D-микрокомпьютерной томографии трабекулярной кости у 52-летнего мужчины с гипопаратиреозом (A) и 59-летнего мужчины без костной патологии (Б) (по материалам M.R. Rubin и соавт., 2010 [54]) ткани (рис. 2 [54]). Гистоморфометрический анализ подтверждает увеличение плотности трабекулярной кости, 3D-микрокомпьютерная томография подвздошной кости демонстрирует нетипичное преобладание пластинчатых трабекул [49-51]. Изображения, полученные с помощью периферической количественной компьютерной томографии высокого разрешения, так же как и гистоморфометрический анализ биопсийного материала из подвздошной кости, показывают, что изменениям подвергается и кортикальная ткань [52, 53].

\section{Диагностика}

Лабораторными показателями, подтверждающими диагноз гипопаратиреоза, являются гипокальциемия, гиперфосфатемия, снижение уровня ПТГ в сыворотке крови.

Наиболее распространенный тест для диагностики гипокальциемии - определение уровня общего кальция в сыворотке крови не менее 2-3 раз с перерывом между исследованиями в 2 недели. Чтобы исключить ложноотрицательные или ложноположительные результаты кальциемии при изменении концентрации плазменных белков, требуется корректировка кальция на уровень альбумина крови. Для расчета скорректированного кальция применяют формулу: общий кальций плазмы (с поправкой) (ммоль/л)= измеренный уровень кальция плазмы (ммоль/л) +0,02×(40 измеренный уровень альбумина плазмы (г/л)). При сомнительных результатах рекомендовано определение уровня ионизированной фракции кальция в сыворотке крови, который в норме находится в референсном диапазоне 1,031,29 ммоль/л.

Измерение содержания ПТГ в крови дает существенную информацию, но вместе с тем его результаты должны быть корректно интерпретированы, так как гипокальциемия может приводить к компенсаторному относительному повышению секреции ПТГ и маскировать истинный гипопаратиреоз. Таким образом, гипокальциемия на фоне нормальной концентрации ПТГ - повод для динамического наблюдения и дообследования пациента.

Согласно европейским клиническим рекомендациям по лечению хронического гипопаратиреоза у взрослых, следует определять уровни магния и 25-гидроксивитамина D как возможные причины гипокальциемии. Рекомендуется исследование почечной функции с оценкой скорости клубочковой фильтрации и суточной экскреции кальция с мочой [55]. 


\section{Лечение}

Целью терапии является контроль симптомов и минимизация осложнений гипокальциемии.

\section{Острая гипокальциемия}

Снижение уровня альбуминскорректированного общего кальция менее 1,9 ммоль/л и/или наличие клинических симптомов гипокальциемии рассматривается как острое состояние и требует проведения экстренных мероприятий [56].

Гипокальциемический криз характеризуется повышенной нервно-рефлекторной возбудимостью. Клинически он проявляется приступами тетании, которым могут предшествовать парестезии лица, кистей и стоп, чувство страха, беспокойство, фибриллярные подергивания отдельных мышц. Чаще всего судороги возникают в мышцах верхних конечностей, реже - в нижних. Вследствие спазма мускулатуры лица возникает сардоническая улыбка, губы приобретают форму «рыбьего рта». При спазме жевательных мышц возникает судорожное сжатие челюстей (тризм). Судороги в мышцах верхних конечностей приводят к характерному положению руки: пальцы сжаты и слегка приведены к ладони, I палец сведен, кисть согнута в лучезапястном суставе («рука акушера»). При спазме мускулатуры нижних конечностей бедра и голени вытянуты, стопы подворачиваются внутрь, туловище выгибается кзади (опистотонус). Вследствие судорожных сокращений межреберных мышц, мышц живота и диафрагмы резко нарушается дыхание. Изменения органов и систем при тетании зависят от преобладания тонуса симпатической или парасимпатической системы. Преобладание тонуса симпатической системы ведет к тахикардии, повышению артериального давления, бледности вследствие спазма периферических сосудов, а парасимпатической - к рвоте, брадикардии, снижению артериального давления, диарее, полиурии. Спазмы гладкой мускулатуры внутренних органов и сосудов могут симулировать сердечно-сосудистые заболевания (приступы стенокардии, эндартериита, мигрени и т.д.), заболевания органов дыхания (например, бронхиальная астма), желудочно-кишечного тракта (холецистит, панкреатит, аппендицит, язва желудка), мочеполовой системы (цистит, нефрит и др.) [57].

Для купирования острой гипокальциемии рекомендуется установка центрального венозного катетера, это позволит предотвратить склерозирование периферических вен вследствие инфузии кальция. Предпочтительно использование глюконата кальция, так как хлорид кальция оказывает более выраженное раздражающее действие на окружающие ткани. Для купирования острой гипокальциемии используется введение глюконата кальция либо болюсно внутривенно 20-40 мл, либо в виде инфузий 60-100 мл в $100-150$ мл 0,9\% раствора $\mathrm{NaCl}$ (или 5\% водного раствора декстрозы) с одновременным назначением препаратов кальция и активных метаболитов/аналогов витамина D. При необходимости продолжения инфузионной терапии введение глюконата кальция может быть продолжено по схеме: 15 мг/кг элементарного кальция (в среднем 10 г глюконата кальция) в 1000 мл 0,9\% раствора $\mathrm{NaCl}$ (или 5\% раствора декстрозы) со скоростью 1-3 мг/кг/час (в среднем в течение 8-10 часов). Цель терапии - нормализация показателей общего и ионизированного кальция на нижней границе референсных значений или несколько ниже в отсутствие клинических симптомов гипокальциемии [56]. Для коррекции терапии необходим частый контроль уровня кальция крови (каждые 6-12 часов в начале лечения, после стабилизации состояния пациента - каждые 24 часа).

Внутривенное введение кальция требует осторожности у больных с гипокалиемией и у пациентов, принимающих дигоксин, в связи с повышенным риском аритмий [2].

Хроническая гипокальциемия

Лечение проводится всем пациентам с хроническим гипопаратиреозом с симптомами гипокальциемии с уровнем альбуминскорректированного общего кальция менее 2 ммоль/л или ионизированного кальция сыворотки крови менее 1 ммоль/л. В случае бессимптомного течения хронического гипопаратиреоза с уровнем общего кальция между 2 ммоль/л и нижней границей референсного диапазона предлагается пробная терапия с последующей оценкой общего самочувствия [55].

Основная цель терапии хронической гипокальциемии - устранение клинической симптоматики и поддержание концентрации общего кальция в сыворотке в пределах 2,1-2,4 ммоль/л при кальциурии не более 10 ммоль/сут. Длительное поддержание кальция на верхней границе референсного диапазона может приводить к выраженной гиперкальциурии вследствие отсутствия эффекта ПТГ на почечные канальцы. В результате возникает риск развития нефролитиаза, нефрокальциноза и хронической почечной недостаточности $[49,58]$.

Стандартная терапия хронической гипокальциемии включает в себя пероральное 
использование солей кальция и препаратов/аналогов витамина D. Как правило, применяется карбонат (40\% элементарного кальция) или цитрат кальция (21\% элементарного кальция) в среднесуточных дозах 1-3 г. К наиболеечасто используемым активным метаболитам витамина D относят альфакальцидол в суточной дозе 0,5-3 мкг (возможно повышение дозы до 6 мкг/сут) и кальцитриол 0,25-2 мкг/сут в 1 или 2 приема [50,51]. У пациентов с хроническим гипопаратиреозом необходимо поддерживать нормальный уровень 25-гидроксивитамина D - 30-50 нг/мл (75-125 нмоль/л). Суточная доза колекальциферола составляет 1000-2000 ME, по показаниям назначают насыщающие дозы препарата. При выявлении стойкой гиперфосфатемии требуется введение гипофосфатной диеты, при необходимости - в сочетании с фосфатбиндерами и коррекцией доз препарата кальция и витамина D $[51,55]$.

Тиазидные диуретики используются для усиления реабсорбции кальция в дистальных почечных канальцах и уменьшения кальциурии. Присоединение тиазидных диуретиков в ряде случаев позволяет добиться снижения дозы препаратов кальция и активного метаболита витамина D [51, 55].

Пациенты с хроническим гипопаратиреозом нуждаются в постоянном динамическом контроле в связи с риском возникновения осложнений, в том числе почечной патологии и кальцификации мягких тканей. Результаты крупного исследования 120 пациентов с хроническим гипопаратиреозом подтверждают высокий риск развития патологии почек на фоне длительной терапии активными метаболитами витамина D и препаратами кальция, средний срок наблюдения составил 7,4 5,1 года. У $38 \%$ больных гиперкальциурия более 8 ммоль/сут (300 мг/сут) отмечалась как минимум в одном измерении. В 31\% наблюдений (у 17 пациентов из 54) по данным ультразвукового исследования и/или компьютерной томографии почек отмечены признаки нефрокальциноза или нефролитиаза. В 52\% случаев (у 16 пациентов из 31) при компьютерной томографии головного мозга диагностирована кальцификация базальных ганглиев. Трети пациентов (42 человека, 33\%) как минимум однократно экстренно потребовался визит к врачу или госпитализация в специализированный стационар в связи с осложнениями гипопаратиреоза. Причины обращения включали в себя симптоматическую гипокальциемию (62\%), симптоматическую гиперкальциемию (12\%) и другие (26\%), в том числе приступы почечной колики и почечных камней и осложнения гемодиализа [50].
Уровни сывороточного кальция, фосфора и креатинина следует определять ежемесячно при первоначальных корректировках доз, с контрольной оценкой 2 раза в год после того, как режим будет стабилизирован. Кальций в моче и уровень креатинина требуется определять 2 раза в год для обнаружения любых почечных токсических эффектов гиперкальциурии. Рекомендуются ежегодные обследования с помощью щелевой лампы, а также офтальмоскопическое исследование у всех пациентов для исключения катаракты $[51,55]$. Согласно рекомендациям европейской рабочей группы по ведению пациентов с хроническим гипопаратиреозом, проведение компьютерной томографии почек показано при наличии у пациента симптомов мочекаменной болезни или в случае роста уровня креатинина. Ввиду повышения показателей МПК при хроническом гипопаратиреозе не рекомендуется регулярное выполнение двухэнергетической рентгеновской абсорбциометрии. Отсутствуют четкие рекомендации о показаниях к выполнению компьютерной томографии головного мозга, тем не менее данное исследование должно проводиться при развитии специфической неврологической симптоматики (головная боль, утомляемость, дизартрия, деградация двигательных функций, деменция, судороги, мышечная спастичность), а также у пациентов с персистирующей гиперфосфатемией $[50,51,55]$.

Гипопаратиреоз - одна из немногих эндокринопатий, для которых заместительная терапия рекомбинантным паратгормоном пока не нашла широкого применения. В настоящее время синтезированы различные препараты рекомбинантного ПТГ, однако вопрос патогенетической терапии и широкого использования синтетического ПТГ у пациентов с гипопаратиреозом остается спорным. Европейская рабочая группа по ведению пациентов с хроническим гипопаратиреозом не рекомендует назначение рекомбинантного паратгормона в рутинной практике, однако не исключается его назначение по индивидуальным показаниям в случае тяжелых, рефрактерных к традиционной терапии форм заболевания [55]. Необходимо отметить, что в США рекомбинантный человеческий паратгормон (1-84) одобрен как дополнение к терапии препаратами кальция и витамина D для контроля гипокальциемии у пациентов с гипопаратиреозом с января 2015 г. [59].

Впервые патогенетическая терапия с использованием синтетического человеческого ПТГ 1-34 (препарат ПТГ (1-34)) при хроническом гипопаратиреозе была изучена в пилотном перекрестном исследовании с участием 10 взрослых 
пациентов. Согласно полученным результатам (срок наблюдения составил 10 недель), при подкожном введении ПТГ (1-34) удается достичь стойкой нормокальциемии и нормокальциурии при назначении препарата 1 раз в сутки. На фоне терапии кальцитриолом по сравнению с ПТГ (1-34) стойкая нормокальциемия сочеталась с увеличением экскреции кальция с мочой, представляющим собой фактор риска развития нефрокальциноза и нефролитиаза [60]. В последующем рандомизированном исследовании продемонстрировано преимущество двукратных

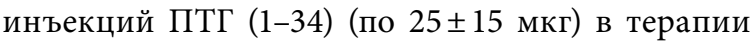
гипопаратиреоза по сравнению с режимом дозирования 1 раз в сутки $(58 \pm 28$ мкг), что проявлялось более быстрым достижением нормокальциемии при использовании меньшей суточной дозы препарата [61].

В трехлетнем сравнительном рандомизированном исследовании 27 пациентов с гипопаратиреозом в возрасте от 18 до 70 лет проводилась оценка эффективности терапии ПТГ (1-34) в режиме двукратных инъекций и комбинированного лечения кальцитриолом и препаратами кальция. В обеих группах сывороточный уровень кальция сохранялся в пределах референсных значений или несколько ниже нормы (1,9-2,2 ммоль/л). Однако выявлена статистически достоверная разница в средних показателях кальциурии, которая была выше в группе кальцитриола. Несмотря на то что терапия ПТГ (1-34) способствовала значительному увеличению биохимических маркеров костного обмена (по сравнению с отсутствием существенных изменений при лечении кальцитриолом), различий в МПК между группами не наблюдалось. Клиренс креатинина существенно не различался и в ходе исследования оставался стабильным в обеих группах [62].

M.R. Rubin и соавт. оценили эффективность использования интактного ПТГ (1-84) у пациентов с хроническим гипопаратиреозом. Всего в исследование, продолжительность которого составила 24 месяца, включены 30 пациентов с аутоиммунным и послеоперационным гипопаратиреозом. ПТГ (1-84) вводился подкожно через день в дозе 100 мкг/сут. До момента включения в исследование у всех пациентов отмечалась стойкая нормокальциемия на фоне терапии препаратами витамина D и кальция, показатели МПК были нормальными или несколько выше возрастных норм. Согласно результатам исследования, значительно уменьшилась потребность в препара-

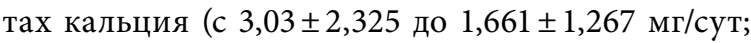
$\mathrm{p}<0,05)$, так же как и в препарате кальцитриола (с 0,68 $\pm 0,5$ до 0,4 $\pm 0,5$ мкг/сут; $\mathrm{p}<0,05$ ). При этом уровни сывороточного кальция и кальциурия оставались в референсном диапазоне на протяжении всего исследования. При оценке МПК выявлен прирост в поясничном отделе позвоночника на $2,9 \pm 4 \%$ от исходного уровня $(\mathrm{p}<0,05)$, тогда как в проксимальном отделе бедренной кости показатели остались без изменений. В дистальной трети лучевой кости, наоборот, отмечено снижение МПК на 2,4 $4 \%(p<0,05)$. Данные изменения МПК свидетельствуют о возможности гормонопосредованного увеличения плотности в трабекулярной костной ткани и вероятной эндостальной резорбции [63]. Подобные эффекты наблюдаются при лечении остеопороза препаратами ПТГ (1-34) [64]. Некоторое снижение показателей МПК не отражает уменьшение общей прочности костной ткани, но говорит об изменении ее объема и микроархитектоники. $3 \mathrm{D}$-микрокомпьютерная томография костей у пациентов с гипопаратиреозом демонстрирует увеличение объема губчатой костной ткани, а также прирост количества и толщины трабекул [54]. Однако влияние этих изменений на прочность кости остается неизвестным.

В 2013 г. проведено двойное слепое плацебоконтролируемое рандомизированное исследование III фазы (REPLACE) продолжительностью более 18 месяцев [59]. В совокупности в него включены 134 пациента в возрасте от 18 до 85 лет из 33 медицинских учреждений. Доза препарата составляла от 50 до 100 мкг в сутки. Результаты показали: терапия ПТГ (1-84) позволяет достичь стойкой нормокальциемии, а также снижения потребности в активных метаболитах витамина D и препаратах кальция. У 54,8\% пациентов, получавших стандартную терапию (кальций, активный метаболит витамина D) в сочетании с ПТГ (1-84), дозы препаратов кальция и витамина D были сокращены на $50 \%$ и более, при этом уровень альбуминскорректированного общего кальция сохранялся в диапазоне от 1,9 до 2,6 ммоль/л. Количество пациентов, которые имели по крайней мере одно нежелательное явление, было сопоставимо: 84 (93\%) пациента в группе лечения ПТГ (1-84) против 44 (100\%) в группе плацебо. К наиболее частым нежелательным явлениям относились гипокальциемия, мышечные спазмы, парестезии, головная боль, тошнота. Доля пациентов с серьезными побочными эффектами также была сопоставима в обеих группах: 10 (11\%) пациентов на терапии ПТГ (1-84) и 4 (9\%) в группе плацебо [59].

Таким образом, результаты проведенных исследований свидетельствуют о перспективах 
использования препаратов рекомбинантного человеческого паратгормона в лечении пациентов с хроническим гипопаратиреозом, особенно в случае тяжелых форм заболевания и наличия сочетанной патологии почечной системы. Однако требуются дополнительные исследования на больших выборках и с более продолжительным периодом наблюдения. Интересными представляются работы, посвященные оценке воздействия рекомбинантного ПТГ на прочность и метаболизм костной ткани у данной группы больных.

\section{Заключение}

В основе успешной терапии гипопаратиреоза лежит понимание причин развития заболевания. Первоначальное обследование пациента с гипокальциемией должно обязательно включать подробный сбор анамнеза. Это позволит вовремя
Конфликт интересов

Авторы подтверждают отсутствие скрытых конфликтов интересов. диагностировать аутоиммунные и редкие генетические формы гипопаратиреоза.

Назначение и применение препаратов кальция и витамина $\mathrm{D}$ должно быть направлено на поддержание баланса между оптимальной концентрацией кальция в сыворотке крови и нормокальциурией. Часто гиперкальциурия недооценивается специалистами, что в последующем приводит к развитию тяжелой почечной патологии - нефрокальциноза и нефролитиаза. Отсутствие своевременной диагностики гипокальциемической кардиомиопатии сопровождается прогрессирующей сердечной недостаточностью и последующей тяжелой инвалидизацией пациента.

Заместительная терапия препаратами рекомбинантного человеческого ПТГ - перспективное направление, особенно в случае тяжелых, рефрактерных к традиционной терапии форм заболевания. (\$)

\section{Литература}

1. Shoback D. Clinical practice. Hypoparathyroidism. N Engl J Med. 2008;359(4):391-403. doi: 10.1056/NEJMcp0803050.

2. Bilezikian JP, Khan A, Potts JT Jr, Brandi ML, Clarke BL, Shoback D, Jüppner $H$, D'Amour P, Fox J, Rejnmark L, Mosekilde L, Rubin MR, Dempster D, Gafni R, Collins MT, Sliney J, Sanders J. Hypoparathyroidism in the adult: epidemiology, diagnosis, pathophysiology, target-organ involvement, treatment, and challenges for future research. J Bone Miner Res. 2011;26(10):2317-37. doi: 10.1002/ jbmr.483.

3. Мокрышева НГ. Первичный гиперпаратиреоз. Эпидемиология, клиника, современные принципы диагностики и лечения. Дис. ... д-ра мед. наук. М.; 2011. 253 с.

4. Мирная СС, Пигарова ЕА, Беляева АВ, Мокрышева НГ, Тюльпаков АН, Рожинская ля. Роль кальций-чувствительного рецептора в поддержании системы кальциевого гомеостаза. Остеопороз и остеопатии. 2010;(3):32-6.

5. Clarke BL, Brown EM, Collins MT, Jüppner $H$, Lakatos P, Levine MA, Mannstadt MM, Bilezikian JP, Romanischen AF, Thakker RV. Epidemiology and diagnosis of hypoparathyroidism. J Clin Endocrinol Metab. 2016;101(6):2284-99. doi: 10.1210/jc.2015-3908.

6. Powers J, Joy K, Ruscio A, Lagast H. Prevalence and incidence of hypoparathyroidism in the United States using a large claims database. J Bone Miner Res. 2013;28(12):2570-6. doi: 10.1002/jbmr.2004.

7. Kakava K, Tournis S, Papadakis G, Karelas I, Stampouloglou P, Kassi E, Triantafillopoulos I, Villiotou V, Karatzas T. Postsurgical hypoparathyroidism: a systematic review. In Vivo. 2016;30(3):171-9.
8. Edafe O, Antakia R, Laskar N, Uttley L, Balasubramanian SP. Systematic review and meta-analysis of predictors of post-thyroidectomy hypocalcaemia. Br J Surg. 2014;101(4): 307-20. doi: 10.1002/bjs.9384.

9. Sitges-Serra A, Ruiz S, Girvent M, Manjón H, Dueñas JP, Sancho JJ. Outcome of protracted hypoparathyroidism after total thyroidectomy. Br J Surg. 2010;97(11):1687-95. doi: 10.1002/ bjs.7219.

10. Marx SJ. Hyperparathyroid and hypoparathyroid disorders. $\mathrm{N}$ Engl J Med. 2000;343(25):1863-75. doi: 10.1056/ NEJM200012213432508.

11. Lorente-Poch L, Sancho JJ, Muñoz-Nova JL, Sánchez-Velázquez P, Sitges-Serra A. Defining the syndromes of parathyroid failure after total thyroidectomy. Gland Surg. 2015;4(1):82-90. doi: 10.3978/j.issn.2227-684X.2014.12.04.

12. Grodski S, Serpell J. Evidence for the role of perioperative PTH measurement after total thyroidectomy as a predictor of hypocalcemia. World J Surg. 2008;32(7):1367-73. doi: 10.1007/s00268-008-9545-5.

13. Lorente-Poch L, Sancho JJ, Ruiz S, Sitges-Serra A. Importance of in situ preservation of parathyroid glands during total thyroidectomy. $\mathrm{Br} J$ Surg. 2015;102(4):359-67. doi: $10.1002 /$ bjs. 9676.

14. Eisenbarth GS, Gottlieb PA. Autoimmune polyendocrine syndromes. $\mathrm{N}$ Engl J Med. 2004;350(20):2068-79. doi: 10.1056/NEJMra030158.

15. Orlova EM, Bukina AM, Kuznetsova ES, Kareva MA, Zakharova EU, Peterkova VA, Dedov II. Autoimmune polyglandular syndrome type 1 in Russian patients: clinical variants and autoimmune regulator mutations. Horm Res Paediatr. 2010;73(6):449-57. doi: 10.1159/000313585.
16. Li Y, Song YH, Rais N, Connor E, Schatz D, Muir A, Maclaren N. Autoantibodies to the extracellular domain of the calcium sensing receptor in patients with acquired hypoparathyroidism. J Clin Invest. 1996;97(4):910-4. doi: 10.1172/JCI118513.

17. Kemp EH, Habibullah M, Kluger N, Ranki A, Sandhu HK, Krohn KJ, Weetman AP. Prevalence and clinical associations of calcium-sensing receptor and NALP5 autoantibodies in Finnish APECED patients. J Clin Endocrinol Metab. 2014;99(3):1064-71. doi: 10.1210/jc.20133723.

18. Kifor O, Moore FD Jr, Delaney M, Garber J, Hendy GN, Butters R, Gao P, Cantor TL, Kifor I, Brown EM, Wysolmerski J. A syndrome of hypocalciuric hypercalcemia caused by autoantibodies directed at the calcium-sensing receptor. J Clin Endocrinol Metab. 2003;88(1):60-72. doi: 10.1210/jc.2002-020249.

19. Alimohammadi $M$, Björklund $P$, Hallgren A, Pöntynen N, Szinnai G, Shikama N, Keller MP, Ekwall O, Kinkel SA, Husebye ES, Gustafsson J, Rorsman F, Peltonen L, Betterle C, Perheentupa J, Akerström G, Westin G, Scott HS, Holländer GA, Kämpe O. Autoimmune polyendocrine syndrome type 1 and NALP5, a parathyroid autoantigen. $\mathrm{N}$ Engl J Med. 2008;358(10):1018-28. doi: 10.1056/ NEJMoa0706487.

20. Meloni A, Willcox N, Meager A, Atzeni M, Wolff AS, Husebye ES, Furcas M, Rosatelli MC, Cao A, Congia M. Autoimmune polyendocrine syndrome type 1: an extensive longitudinal study in Sardinian patients. J Clin Endocrinol Metab. 2012;97(4):1114-24. doi: 10.1210/ jc.2011-2461.

21. Kifor O, McElduff A, LeBoff MS, Moore FD Jr, Butters R, Gao P, Cantor TL, Kifor I, Brown EM. 
Activating antibodies to the calcium-sensing receptor in two patients with autoimmune hypoparathyroidism. J Clin Endocrinol Metab. 2004;89(2):548-56. doi: 10.1210/jc.2003031054.

22. Brown EM, Gamba G, Riccardi D, Lombardi M, Butters R, Kifor O, Sun A, Hediger MA, Lytton J, Hebert SC. Cloning and characterization of an extracellular $\mathrm{Ca}(2+)$-sensing receptor from bovine parathyroid. Nature. 1993;366(6455): 575-80. doi: 10.1038/366575a0

23. Thakker RV. Diseases associated with the extracellular calcium-sensing receptor. Cell Calcium. 2004;35(3):275-82.

24. Watanabe $\mathrm{S}$, Fukumoto $\mathrm{S}$, Chang $\mathrm{H}$, Takeuchi $\mathrm{Y}$, Hasegawa Y, Okazaki R, Chikatsu N, Fujita T. Association between activating mutations of calcium-sensing receptor and Bartter's syndrome. Lancet. 2002;360(9334):692-4. doi: 10.1016/S0140-6736(02)09842-2.

25. Vargas-Poussou R, Huang $C$, Hulin P, Houillier $P$, Jeunemaître $X$, Paillard $M$, Planelles $G$, Déchaux M, Miller RT, Antignac C. Functional characterization of a calcium-sensing receptor mutation in severe autosomal dominant hypocalcemia with a Bartter-like syndrome. J Am Soc Nephrol. 2002;13(9):2259-66.

26. Grigorieva IV, Thakker RV. Transcription factors in parathyroid development: lessons from hypoparathyroid disorders. Ann N Y Acad Sci. 2011;1237:24-38. doi: 10.1111/j.17496632.2011.06221.x.

27. Datta R, Waheed A, Shah GN, Sly WS. Signal sequence mutation in autosomal dominant form of hypoparathyroidism induces apoptosis that is corrected by a chemical chaperone. Proc Natl Acad Sci U S A. 2007;104(50):19989-94. doi: 10.1073/pnas.0708725104.

28. Mannstadt M, Kronenberg HM. Parathyroid hormone gene: structure, evoluation, and regulation. In: Bilezikian JP, Marcus R, Levine MA, Claudio Marcocci C, Silverberg SJ, Potts JT. The parathyroids: basic and clinical concepts. $3^{\text {rd }}$ edition. Elsevier; 2015. p. 590-3.

29. Goldmuntz E. DiGeorge syndrome: new insights. Clin Perinatol. 2005;32(4):963-78, ix-x. doi: 10.1016/j.clp.2005.09.006.

30. Thakker RV. Genetic developments in hypoparathyroidism. Lancet. 2001;357(9261): 974-6. doi: http://dx.doi.org/10.1016/S01406736(00)04254-9.

31. Sanjad SA, Sakati NA, Abu-Osba YK, Kaddoura R, Milner RD. A new syndrome of congenital hypoparathyroidism, severe growth failure, and dysmorphic features. Arch Dis Child. 1991;66(2):193-6.

32. Maceluch JA, Niedziela M. The clinical diagnosis and molecular genetics of kearns-sayre syndrome: a complex mitochondrial encephalomyopathy. Pediatr Endocrinol Rev. 20062007;4(2):117-37.

33. Mantovani G. Clinical review: Pseudohypoparathyroidism: diagnosis and treatment
J Clin Endocrinol Metab. 2011;96(10):3020-30. doi: 10.1210/jc.2011-1048.

34. Bastepe M. The GNAS locus and pseudohypoparathyroidism. Adv Exp Med Biol. 2008;626:27-40.

35. Vetter T, Lohse MJ. Magnesium and the parathyroid. Curr Opin Nephrol Hypertens. 2002;11(4):403-10.

36. Paunier L, Radde IC, Kooh SW, Conen PE, Fraser D. Primary hypomagnesemia with secondary hypocalcemia in an infant. Pediatrics. 1968;41(2):385-402.

37. Okazaki R, Chikatsu N, Nakatsu M, Takeuchi Y, Ajima M, Miki J, Fujita T, Arai M, Totsuka Y, Tanaka K, Fukumoto S. A novel activating mutation in calcium-sensing receptor gene associated with a family of autosomal dominant hypocalcemia. J Clin Endocrinol Metab. 1999;84(1): 363-6. doi: 10.1210/jcem.84.1.5385.

38.Потемкин ВВ, ред. Эндокринология: руководство для врачей. М.: Медицинское информационное агентство; 2013.776 с.

39. Schaaf M, Payne CA. Effect of diphenylhydantoin and phenobarbital on overt and latent tetany. N Engl J Med. 1966;274(22):1228-33. doi: 10.1056/NEJM196606022742203.

40. Ballane GT, Sfeir JG, Dakik HA, Brown EM, ElHajj Fuleihan G. Use of recombinant human parathyroid hormone in hypocalcemic cardiomyopathy. Eur J Endocrinol. 2012;166(6): 1113-20. doi: 10.1530/EJE-11-1094.

41. Murros J, Luomanmäki K. A case of hypocalcemia, heart failure and exceptional repolarization disturbances. Acta Med Scand. 1980;208(1-2):133-6. doi: 10.1111/j.09546820.1980.tb01166.x.

42. Rentoukas E, Lazaros G, Sotiriou S, Athanassiou M, Tsiachris D, Deftereos S, Stefanadis C. Extreme but not life-threatening QT interval prolongation? Take a closer look at the neck! J Electrocardiol. 2013;46(2):128-30. doi: 10.1016/j.jelectrocard.2012.10.007.

43. Meena D, Prakash M, Gupta Y, Bhadada SK, Khandelwal N. Carotid, aorta and renal arteries intima-media thickness in patients with sporadic idiopathic hypoparathyroidism. Indian J Endocrinol Metab. 2015;19(2):262-6. doi: 10.4103/2230-8210.149320

44. Cohen $\mathrm{Gl}$, Aboufakher R, Bess R, Frank J, Othman M, Doan D, Mesiha N, Rosman HS, Szpunar S. Relationship between carotid disease on ultrasound and coronary disease on CT angiography. JACC Cardiovasc Imaging. 2013;6(11):1160-7. doi: 10.1016/j. jcmg.2013.06.007.

45. Agarwal P, Prakash M, Singhal M, Bhadada SK, Gupta Y, Khandelwal N. To assess vascular calcification in the patients of hypoparathyroidism using multidetector computed tomography scan. Indian J Endocrinol Metab. 2015;19(6): 785-90. doi: 10.4103/2230-8210.167545.

46. Bolland MJ, Grey A, Avenell A, Gamble GD, Reid IR. Calcium supplements with or without vitamin D and risk of cardiovascular events: reanalysis of the Women's Health Initiative limited access dataset and meta-analysis. BMJ. 2011;342:d2040. doi: 10.1136/bmj.d2040.

47. Srirangarajan S, Satyanarayan A, Ravindra S, Thakur S. Dental manifestation of primary idiopathic hypoparathyroidism. J Indian Soc Periodontol. 2014;18(4):524-6. doi: 10.4103/0972124X.138755.

48. Minisola S, Dionisi S, Pacitti MT, Paglia F, Carnevale V, Scillitani A, Mazzaferro S, De GS, Pepe J, Derasmo E, Romagnoli E. Gender differences in serum markers of bone resorption in healthy subjects and patients with disorders affecting bone. Osteoporos Int. 2002;13(2):171-5.

49. Rubin MR, Dempster DW, Zhou H, Shane E, Nickolas T, Sliney J Jr, Silverberg SJ, Bilezikian JP. Dynamic and structural properties of the skeleton in hypoparathyroidism. J Bone Miner Res. 2008;23(12):2018-24. doi: 10.1359/ jbmr.080803.

50. Mitchell DM, Regan S, Cooley MR, Lauter KB, Vrla MC, Becker CB, Burnett-Bowie SA, Mannstadt $\mathrm{M}$. Long-term follow-up of patients with hypoparathyroidism. J Clin Endocrinol Metab. 2012;97(12):4507-14. doi: 10.1210/jc.20121808.

51. Stack BC Jr, Bimston DN, Bodenner DL, Brett EM, Dralle H, Orloff LA, Pallota J, Snyder SK, Wong RJ, Randolph GW. American Association of Clinical Endocrinologists and American College of Endocrinology Disease state clinical review: postoperative hypoparathyroidism - definitions and management. Endocr Pract. 2015;21(6):674-85. doi: 10.4158/ EP14462.DSC

52. Chen Q, Kaji H, lu MF, Nomura R, Sowa H, Yamauchi M, Tsukamoto T, Sugimoto T, Chihara K. Effects of an excess and a deficiency of endogenous parathyroid hormone on volumetric bone mineral density and bone geometry determined by peripheral quantitative computed tomography in female subjects. J Clin Endocrinol Metab. 2003;88(10):4655-8. doi: 10.1210/jc.2003-030470.

53. Dempster D. Bone histomorphometry in hypoparathyroidism. In: Brandi ML, Brown EM, editors. Hypoparathyroidism. New York: Springer; 2015. p. 287-96.

54. Rubin MR, Dempster DW, Kohler T, Stauber M, Zhou H, Shane E, Nickolas T, Stein E, Sliney J Jr, Silverberg SJ, Bilezikian JP, Müller R. Three dimensional cancellous bone structure in hypoparathyroidism. Bone. 2010;46(1):190-5. doi: 10.1016/j.bone.2009.09.020

55. Bollerslev J, Rejnmark L, Marcocci C, Shoback DM, Sitges-Serra A, van Biesen W, Dekkers OM; European Society of Endocrinology. European Society of Endocrinology Clinical Guideline: Treatment of chronic hypoparathyroidism in adults. Eur J Endocrinol. 2015;173(2):G1-20. doi: 10.1530/EJE-15-0628. 
56. Society for Endocrinology. Emergency Endocrine Guidance - Acute hypocalcaemia (for use in adult patients), 2013 [Internet]. Available from: http://www.gloshospitals.nhs.uk/ Diabetes/Diabetes\%20Web\%20Documents/ Emergency\%20Guidance\%20Acute\%20Hypocalcaemia\%20in\%20Adults.pdf.

57. Fong J, Khan A. Hypocalcemia: updates in diagnosis and management for primary care. Can Fam Physician. 2012;58(2):158-62.

58. Arlt W, Fremerey C, Callies F, Reincke M, Schneider $\mathrm{P}$, Timmermann W, Allolio B. Well-being, mood and calcium homeostasis in patients with hypoparathyroidism receiving standard treatment with calcium and vitamin D. Eur J Endocrinol. 2002;146(2):215-22.

59. Mannstadt M, Clarke BL, Vokes T, Brandi ML, Ranganath L, Fraser WD, Lakatos $P$, Bajnok L, Garceau R, Mosekilde L, Lagast H, Shoback D,

\section{References}

1. Shoback D. Clinical practice. Hypoparathyroidism. N Engl J Med. 2008;359(4):391-403. doi: 10.1056/NEJMcp0803050.

2. Bilezikian JP, Khan A, Potts JT Jr, Brandi $M L$, Clarke BL, Shoback $D$, Jüppner $H$, D'Amour P, Fox J, Rejnmark L, Mosekilde L, Rubin MR, Dempster D, Gafni R, Collins MT, Sliney J, Sanders J. Hypoparathyroidism in the adult: epidemiology, diagnosis, pathophysiology, target-organ involvement, treatment, and challenges for future research. J Bone Miner Res. 2011;26(10):2317-37. doi: 10.1002/ jbmr.483.

3. Mokrysheva NG. Pervichnyy giperparatireoz. Epidemiologiya, klinika, sovremennye printsipy diagnostiki i lecheniya [Primary hypoparathyroidism. Epidemiology, clinical manifestation, current principles of diagnosis and treatment] [dissertation]. Moscow; 2011. 253 p. (in Russian).

4. Mirnaya SS, Pigarova EA, Belyaeva AV, Mokrysheva NG, Tyul'pakov AN, Rozhinskaya LYa. Rol' kal'tsiy-chuvstvitel'nogo retseptora v podderzhanii sistemy kal'tsievogo gomeostaza [The role of calcium-sensitive receptor in maintenance of calcium homeostasis]. Osteoporoz i osteopatii [Osteoporosis and osteopathy]. 2010;(3):32-6 (in Russian).

5. Clarke BL, Brown EM, Collins MT, Jüppner $H$, Lakatos P, Levine MA, Mannstadt MM, Bilezikian JP, Romanischen AF, Thakker RV. Epidemiology and diagnosis of hypoparathyroidism. J Clin Endocrinol Metab. 2016;101(6):2284-99. doi: 10.1210/jc.2015-3908.

6. Powers J, Joy K, Ruscio A, Lagast H. Prevalence and incidence of hypoparathyroidism in the United States using a large claims database. J Bone Miner Res. 2013;28(12):2570-6. doi: 10.1002/jbmr.2004.

7. Kakava K, Tournis S, Papadakis G, Karelas I, Stampouloglou P, Kassi E, Triantafillopoulos I,
Bilezikian JP. Efficacy and safety of recombinant human parathyroid hormone (1-84) in hypoparathyroidism (REPLACE): a double-blind, placebo-controlled, randomised, phase 3 study. Lancet Diabetes Endocrinol. 2013;1(4): 275-83. doi: 10.1016/S2213-8587(13)70106-2.

60. Winer KK, Yanovski JA, Cutler GB Jr. Synthetic human parathyroid hormone 1-34 vs calcitriol and calcium in the treatment of hypoparathyroidism. JAMA. 1996;276(8):631-6. doi: 10.1001/jama.1996.03540080053029.

61. Winer KK, Yanovski JA, Sarani B, Cutler GB Jr. A randomized, cross-over trial of once-daily versus twice-daily parathyroid hormone 1-34 in treatment of hypoparathyroidism. J Clin Endocrinol Metab. 1998;83(10):3480-6. doi: 10.1210/jcem.83.10.5185.

62. Winer KK, Ko CW, Reynolds JC, Dowdy K, Keil M, Peterson D, Gerber LH, McGarvey C,

Villiotou V, Karatzas T. Postsurgical hypoparathyroidism: a systematic review. In Vivo. 2016;30(3):171-9.

8. Edafe O, Antakia R, Laskar N, Uttley L, Balasubramanian SP. Systematic review and meta-analysis of predictors of post-thyroidectomy hypocalcaemia. Br J Surg. 2014;101(4): 307-20. doi: 10.1002/bjs.9384.

9. Sitges-Serra A, Ruiz S, Girvent M, Manjón $H$, Dueñas JP, Sancho JJ. Outcome of protracted hypoparathyroidism after total thyroidectomy. Br J Surg. 2010;97(11):1687-95. doi: 10.1002/ bjs.7219.

10. Marx SJ. Hyperparathyroid and hypoparathyroid disorders. N Engl J Med. 2000;343(25):1863-75. doi: 10.1056/ NEJM200012213432508.

11. Lorente-Poch L, Sancho JJ, Muñoz-Nova JL, Sánchez-Velázquez P, Sitges-Serra A. Defining the syndromes of parathyroid failure after total thyroidectomy. Gland Surg. 2015;4(1):82-90. doi: 10.3978/j.issn.2227-684X.2014.12.04.

12. Grodski S, Serpell J. Evidence for the role of perioperative PTH measurement after total thyroidectomy as a predictor of hypocalcemia. World J Surg. 2008;32(7):1367-73. doi: 10.1007/s00268-008-9545-5.

13. Lorente-Poch L, Sancho JJ, Ruiz S, Sitges-Serra A. Importance of in situ preservation of parathyroid glands during total thyroidectomy. Br J Surg. 2015;102(4):359-67. doi: 10.1002/bjs.9676.

14. Eisenbarth GS, Gottlieb PA. Autoimmune polyendocrine syndromes. N Engl J Med. 2004;350(20):2068-79. doi: 10.1056/NEJMra030158.

15. Orlova EM, Bukina AM, Kuznetsova ES, Kareva MA, Zakharova EU, Peterkova VA, Dedov II. Autoimmune polyglandular syndrome type 1 in Russian patients: clinical variants and autoimmune regulator mutations.
Cutler GB Jr. Long-term treatment of hypoparathyroidism: a randomized controlled study comparing parathyroid hormone-(1-34) versus calcitriol and calcium. J Clin Endocrinol Metab. 2003;88(9):4214-20. doi: 10.1210/ jc.2002-021736.

63. Rubin MR, Sliney J Jr, McMahon DJ, Silverberg SJ, Bilezikian JP. Therapy of hypoparathyroidism with intact parathyroid hormone. Osteoporos Int. 2010;21(11):1927-34. doi: 10.1007/s00198-009-1149-x.

64. Neer RM, Arnaud CD, Zanchetta JR, Prince R, Gaich GA, Reginster JY, Hodsman AB, Eriksen EF, Ish-Shalom S, Genant HK, Wang O, Mitlak BH. Effect of parathyroid hormone (1-34) on fractures and bone mineral density in postmenopausal women with osteoporosis. N Engl J Med. 2001;344(19):1434-41. doi: 10.1056/ NEJM200105103441904.

Horm Res Paediatr. 2010;73(6):449-57. doi: 10.1159/000313585.

16. Li Y, Song YH, Rais N, Connor E, Schatz D, Muir A, Maclaren N. Autoantibodies to the extracellular domain of the calcium sensing receptor in patients with acquired hypoparathyroidism. J Clin Invest. 1996;97(4):910-4. doi: 10.1172/JCI118513.

17.Kemp EH, Habibullah M, Kluger N, Ranki A, Sandhu HK, Krohn KJ, Weetman AP. Prevalence and clinical associations of calcium-sensing receptor and NALP5 autoantibodies in Finnish APECED patients. J Clin Endocrinol Metab. 2014;99(3):1064-71. doi: 10.1210/jc.20133723.

18. Kifor O, Moore FD Jr, Delaney M, Garber J, Hendy GN, Butters R, Gao P, Cantor TL, Kifor I, Brown EM, Wysolmerski J. A syndrome of hypocalciuric hypercalcemia caused by autoantibodies directed at the calcium-sensing receptor. J Clin Endocrinol Metab. 2003;88(1):60-72. doi: 10.1210/jc.2002-020249.

19. Alimohammadi $M$, Björklund $P$, Hallgren A, Pöntynen N, Szinnai G, Shikama N, Keller MP, Ekwall O, Kinkel SA, Husebye ES, Gustafsson J, Rorsman F, Peltonen L, Betterle C, Perheentupa J, Akerström G, Westin G, Scott HS, Holländer GA, Kämpe O. Autoimmune polyendocrine syndrome type 1 and NALP5, a parathyroid autoantigen. $\mathrm{N}$ Engl J Med. 2008;358(10):1018-28. doi: 10.1056/ NEJMoa0706487.

20. Meloni A, Willcox N, Meager A, Atzeni M, Wolff AS, Husebye ES, Furcas M, Rosatelli MC, Cao A, Congia M. Autoimmune polyendocrine syndrome type 1: an extensive longitudinal study in Sardinian patients. J Clin Endocrinol Metab. 2012;97(4):1114-24. doi: 10.1210/ jc.2011-2461.

21. Kifor O, McElduff A, LeBoff MS, Moore FD Jr, Butters R, Gao P, Cantor TL, Kifor I, Brown EM. 
Activating antibodies to the calcium-sensing receptor in two patients with autoimmune hypoparathyroidism. J Clin Endocrinol Metab. 2004;89(2):548-56. doi: 10.1210/jc.2003031054.

22. Brown EM, Gamba G, Riccardi D, Lombardi M, Butters R, Kifor O, Sun A, Hediger MA, Lytton J, Hebert SC. Cloning and characterization of an extracellular $\mathrm{Ca}(2+)$-sensing receptor from bovine parathyroid. Nature. 1993;366(6455): 575-80. doi: 10.1038/366575a0.

23. Thakker RV. Diseases associated with the extracellular calcium-sensing receptor. Cell Calcium. 2004;35(3):275-82.

24. Watanabe $\mathrm{S}$, Fukumoto $\mathrm{S}$, Chang $\mathrm{H}$, Takeuchi $\mathrm{Y}$, Hasegawa Y, Okazaki R, Chikatsu N, Fujita T. Association between activating mutations of calcium-sensing receptor and Bartter's syndrome. Lancet. 2002;360(9334):692-4. doi: 10.1016/S0140-6736(02)09842-2.

25. Vargas-Poussou R, Huang $C$, Hulin P, Houillier $P$, Jeunemaître $X$, Paillard $M$, Planelles $G$, Déchaux M, Miller RT, Antignac C. Functional characterization of a calcium-sensing receptor mutation in severe autosomal dominant hypocalcemia with a Bartter-like syndrome. J Am Soc Nephrol. 2002;13(9):2259-66.

26. Grigorieva IV, Thakker RV. Transcription factors in parathyroid development: lessons from hypoparathyroid disorders. Ann N Y Acad Sci. 2011;1237:24-38. doi: 10.1111/j.17496632.2011.06221.x.

27. Datta R, Waheed A, Shah GN, Sly WS. Signal sequence mutation in autosomal dominant form of hypoparathyroidism induces apoptosis that is corrected by a chemical chaperone. Proc Natl Acad Sci U S A. 2007;104(50):19989-94. doi: 10.1073/pnas.0708725104.

28. Mannstadt M, Kronenberg HM. Parathyroid hormone gene: structure, evoluation, and regulation. In: Bilezikian JP, Marcus R, Levine MA, Claudio Marcocci C, Silverberg SJ, Potts JT. The parathyroids: basic and clinical concepts. $3^{\text {rd }}$ edition. Elsevier; 2015. p. 590-3.

29. Goldmuntz E. DiGeorge syndrome: new insights. Clin Perinatol. 2005;32(4):963-78, ix-x. doi: 10.1016/j.clp.2005.09.006.

30. Thakker RV. Genetic developments in hypoparathyroidism. Lancet. 2001;357(9261): 974-6. doi: http://dx.doi.org/10.1016/S01406736(00)04254-9.

31. Sanjad SA, Sakati NA, Abu-Osba YK, Kaddoura R, Milner RD. A new syndrome of congenital hypoparathyroidism, severe growth failure, and dysmorphic features. Arch Dis Child. 1991;66(2):193-6.

32. Maceluch JA, Niedziela M. The clinical diagnosis and molecular genetics of kearns-sayre syndrome: a complex mitochondrial encephalomyopathy. Pediatr Endocrinol Rev. 20062007;4(2):117-37.

33. Mantovani G. Clinical review: Pseudohypoparathyroidism: diagnosis and treatment.
J Clin Endocrinol Metab. 2011;96(10):3020-30. doi: 10.1210/jc.2011-1048.

34. Bastepe M. The GNAS locus and pseudohypoparathyroidism. Adv Exp Med Biol. 2008;626:27-40.

35. Vetter T, Lohse MJ. Magnesium and the parathyroid. Curr Opin Nephrol Hypertens. 2002;11(4):403-10.

36. Paunier L, Radde IC, Kooh SW, Conen PE, Fraser D. Primary hypomagnesemia with secondary hypocalcemia in an infant. Pediatrics. 1968;41(2):385-402.

37. Okazaki R, Chikatsu N, Nakatsu M, Takeuchi Y Ajima M, Miki J, Fujita T, Arai M, Totsuka Y, Tanaka K, Fukumoto S. A novel activating mutation in calcium-sensing receptor gene associated with a family of autosomal dominant hypocalcemia. J Clin Endocrinol Metab. 1999;84(1): 363-6. doi: 10.1210/jcem.84.1.5385.

38. Potemkin VV, editor. Endokrinologiya: rukovodstvo dlya vrachey [Endocrinology: a manual for physicians]. Moscow: Meditsinskoe informatsionnoe agentstvo; 2013. 776 p. (in Russian).

39. Schaaf M, Payne CA. Effect of diphenylhydantoin and phenobarbital on overt and latent tetany. N Engl J Med. 1966;274(22):1228-33. doi: 10.1056/NEJM196606022742203.

40. Ballane GT, Sfeir JG, Dakik HA, Brown EM, ElHajj Fuleihan G. Use of recombinant human parathyroid hormone in hypocalcemic cardiomyopathy. Eur J Endocrinol. 2012;166(6): 1113-20. doi: 10.1530/EJE-11-1094.

41. Murros J, Luomanmäki K. A case of hypocalcemia, heart failure and exceptional repolarization disturbances. Acta Med Scand. 1980;208(1-2):133-6. doi: 10.1111/j.09546820.1980.tb01166.x.

42. Rentoukas $E$, Lazaros $G$, Sotiriou S, Athanassiou $M$, Tsiachris $D$, Deftereos $S$, Stefanadis $C$. Extreme but not life-threatening QT interval prolongation? Take a closer look at the neck! J Electrocardiol. 2013;46(2):128-30. doi: 10.1016/j.jelectrocard.2012.10.007.

43. Meena D, Prakash M, Gupta Y, Bhadada SK Khandelwal N. Carotid, aorta and renal arteries intima-media thickness in patients with sporadic idiopathic hypoparathyroidism. Indian J Endocrinol Metab. 2015;19(2):262-6. doi: 10.4103/2230-8210.149320.

44. Cohen Gl, Aboufakher R, Bess R, Frank J, Othman M, Doan D, Mesiha N, Rosman HS Szpunar S. Relationship between carotid disease on ultrasound and coronary disease on CT angiography. JACC CardiovasC Imaging. 2013;6(11):1160-7. doi: 10.1016/j. jcmg.2013.06.007.

45. Agarwal P, Prakash M, Singhal M, Bhadada SK, Gupta Y, Khandelwal N. To assess vascular calcification in the patients of hypoparathyroidism using multidetector computed tomography scan. Indian J Endocrinol Metab. 2015;19(6): 785-90. doi: 10.4103/2230-8210.167545.
46. Bolland MJ, Grey A, Avenell A, Gamble GD, Reid IR. Calcium supplements with or without vitamin D and risk of cardiovascular events: reanalysis of the Women's Health Initiative limited access dataset and meta-analysis. BMJ. 2011;342:d2040. doi: 10.1136/bmj.d2040.

47. Srirangarajan S, Satyanarayan A, Ravindra S, Thakur S. Dental manifestation of primary idiopathic hypoparathyroidism. J Indian Soc Periodontol. 2014;18(4):524-6. doi: 10.4103/0972$124 X .138755$.

48. Minisola S, Dionisi S, Pacitti MT, Paglia F, Carnevale V, Scillitani A, Mazzaferro S, De GS, Pepe J, Derasmo E, Romagnoli E. Gender differences in serum markers of bone resorption in healthy subjects and patients with disorders affecting bone. Osteoporos Int. 2002;13(2):171-5.

49. Rubin MR, Dempster DW, Zhou H, Shane E, Nickolas T, Sliney J Jr, Silverberg SJ, Bilezikian JP. Dynamic and structural properties of the skeleton in hypoparathyroidism. J Bone Miner Res. 2008;23(12):2018-24. doi: 10.1359/ jbmr.080803.

50. Mitchell DM, Regan S, Cooley MR, Lauter KB, Vrla MC, Becker CB, Burnett-Bowie SA, Mannstadt $M$. Long-term follow-up of patients with hypoparathyroidism. J Clin Endocrinol Metab. 2012;97(12):4507-14. doi: 10.1210/jc.20121808.

51. Stack BC Jr, Bimston DN, Bodenner DL, Brett EM, Dralle H, Orloff LA, Pallota J, Snyder SK, Wong RJ, Randolph GW. American Association of Clinical Endocrinologists and American College of Endocrinology Disease state clinical review: postoperative hypoparathyroidism - definitions and management. Endocr Pract. 2015;21(6):674-85. doi: 10.4158/ EP14462.DSC

52. Chen Q, Kaji H, lu MF, Nomura R, Sowa H, Yamauchi M, Tsukamoto T, Sugimoto T, Chihara K. Effects of an excess and a deficiency of endogenous parathyroid hormone on volumetric bone mineral density and bone geometry determined by peripheral quantitative computed tomography in female subjects. J Clin Endocrinol Metab. 2003;88(10):4655-8. doi: 10.1210/jc.2003-030470.

53. Dempster D. Bone histomorphometry in hypoparathyroidism. In: Brandi ML, Brown EM, editors. Hypoparathyroidism. New York: Springer; 2015. p. 287-96.

54. Rubin MR, Dempster DW, Kohler T, Stauber M, Zhou H, Shane E, Nickolas T, Stein E, Sliney J Jr, Silverberg SJ, Bilezikian JP, Müller R. Three dimensional cancellous bone structure in hypoparathyroidism. Bone. 2010;46(1):190-5. doi: 10.1016/j.bone.2009.09.020

55. Bollerslev J, Rejnmark L, Marcocci C, Shoback DM, Sitges-Serra A, van Biesen W, Dekkers OM; European Society of Endocrinology. European Society of Endocrinology Clinical Guideline: Treatment of chronic hypoparathyroidism in adults. Eur J Endocri- 
nol. 2015;173(2):G1-20. doi: 10.1530/EJE-150628.

56. Society for Endocrinology. Emergency Endocrine Guidance - Acute hypocalcaemia (for use in adult patients), 2013 [Internet]. Available from: http://www.gloshospitals.nhs.uk/ Diabetes/Diabetes\%20Web\%20Documents/ Emergency\%20Guidance\%20Acute\%20Hypocalcaemia\%20in\%20Adults.pdf.

57. Fong J, Khan A. Hypocalcemia: updates in diagnosis and management for primary care. Can Fam Physician. 2012;58(2):158-62.

58. Arlt W, Fremerey C, Callies F, Reincke M, Schneider P, Timmermann W, Allolio B. Well-being, mood and calcium homeostasis in patients with hypoparathyroidism receiving standard treatment with calcium and vitamin D. Eur J Endocrinol. 2002;146(2):215-22.

59. Mannstadt M, Clarke BL, Vokes T, Brandi ML, Ranganath L, Fraser WD, Lakatos P, Bajnok L,
Garceau R, Mosekilde L, Lagast H, Shoback D, Bilezikian JP. Efficacy and safety of recombinant human parathyroid hormone (1-84) in hypoparathyroidism (REPLACE): a double-blind, placebo-controlled, randomised, phase 3 study. Lancet Diabetes Endocrinol. 2013;1(4): 275-83. doi: 10.1016/S2213-8587(13)70106-2.

60. Winer KK, Yanovski JA, Cutler GB Jr. Synthetic human parathyroid hormone 1-34 vs calcitriol and calcium in the treatment of hypoparathyroidism. JAMA. 1996;276(8):631-6. doi:10.1001/jama.1996.03540080053029.

61. Winer KK, Yanovski JA, Sarani B, Cutler GB Jr. $A$ randomized, cross-over trial of once-daily versus twice-daily parathyroid hormone 1-34 in treatment of hypoparathyroidism. J Clin Endocrinol Metab. 1998;83(10):3480-6. doi: 10.1210/jcem.83.10.5185.

62. Winer KK, Ko CW, Reynolds JC, Dowdy K, Keil M, Peterson D, Gerber LH, McGarvey C,

\title{
Hypoparathyroidism: etiology, clinical manifestation, current diagnostics and treatment
}

\author{
Mokrysheva N.G. • Eremkina A.K. • Kovaleva E.V. ${ }^{1}$
}

Parathyroid hormone (PTH) is the main regulator of calcium and phosphorus metabolism. PTH deficiency or tissue resistance to its effects results in hypoparathyroidism characterized by low serum calcium and elevated serum phosphate levels. The most common is post-operative hypoparathyroidism caused by an inadvertent damage or removal of the parathyroid glands, deterioration of blood supply to the neck region, most often during thyroid surgery. The second common form of the disease is the autoimmune one related with immune destruction of parathyroid cells. Less frequent causes of hypoparathyroidism include a variety of genetic syndromes, mitochondrial genome defects, and hypomagnesemia. The main signs and symptoms of hypoparathyroidism are related to hypocalcaemia and hyperphosphatemia land result in increased neuromuscular irritability and general autonomic reactivity, with finger and toe tingling, muscle cramps, tonic seizures, laryngo- and bronchospasm, and neurosis. These symptoms are closely associated with serum calcium levels; their severity depends on the degree of hypocalcaemia. Laboratory parameters confirming the diagnosis of hypoparathyroidism are hypocalcaemia, hyperphosphatemia, and reduced serum PTH. Treatment of hypoparathyroidism involves management of hypocalcaemic crisis and maintenance therapy. Acute hypocalcaemia, a potentially life-threatening condition, is treated as an emergency with intravenous calcium combined with oral calcium and active vitamin D. Standard chronic treatment for hypoparathyroidism is based on oral calcium and active metabolites of vitamin $D /$ vitamin $D$ analogs and is aimed at the balance between optimal low-normal serum calcium concentrations and normocalciuria. Worsening hypercalciuria is often underestimated by specialists, although it can cause severe renal problems, such as nephrocalcinosis and neprolithiasis. Hypoparathyroidism is one of the few endocrine deficiencies for which replacement treatment with recombinant PTH is not widely used. Replacement therapy with recombinant human PTH is a promising area, especially in severe clinical cases, refractory to conventional treatment.

Key words: hypoparathyroidism, pseudohypoparathyroidism, parathyroid hormone (PTH), hypocalcaemia, hyperphosphatemia, recombinant human PTH 1-84

doi: 10.18786/2072-0505-2016-44-4-477-492
Cutler GB Jr. Long-term treatment of hypoparathyroidism: a randomized controlled study comparing parathyroid hormone-(1-34) versus calcitriol and calcium. J Clin Endocrinol Metab. 2003;88(9):4214-20. doi: 10.1210/ jc.2002-021736.

63. Rubin MR, Sliney J Jr, McMahon DJ, Silverberg SJ, Bilezikian JP. Therapy of hypoparathyroidism with intact parathyroid hormone. Osteoporos Int. 2010;21(11):1927-34. doi: 10.1007/s00198-009-1149-x.

64. Neer RM, Arnaud CD, Zanchetta JR, Prince R, Gaich GA, Reginster JY, Hodsman AB, Eriksen EF, Ish-Shalom S, Genant HK, Wang O, Mitlak BH. Effect of parathyroid hormone (1-34) on fractures and bone mineral density in postmenopausal women with osteoporosis. N Engl J Med. 2001;344(19):1434-41. doi: 10.1056/ NEJM200105103441904.
Mokrysheva Natalia G. - MD, PhD, Head of Parathyroid Glands Pathology Centre ${ }^{1}$

Eremkina Anna K. - MD, PhD, Research Fellow, Parathyroid Glands Pathology Centre ه 11 Dmitriya Ul'yanova ul., Moscow, 117036, Russian Federation. Tel.: +7 (495) 5000063. E-mail: parathyroid.enc.@gmail.com

Kovaleva Elena V. - Resident ${ }^{1}$
'Endocrinology Research Center; 11 Dmitriya Ul'yanova ul., Moscow, 117036, Russian Federation 